\title{
Performance of Smart Farming through Drip Irrigation and Managing of Fertilizers and Pesticides through IoT and GSM
}

\author{
D. Louisa Mary, M. Ramakrishnan, A. Abraham N R Singh
}

\begin{abstract}
In conventional farming the growth of the plant of interest is manually monitored by human senses, which needs high degree of sense perceptions and it always has a high quantum of error. If the farming is made automated with IoT applications, it can be done with utmost precision and accuracy. Human interventions can be minimized. Thus the efficiency of the cultivation can be enhanced and utilization of materials like water, fertilizers can be optimized. In IoT-based Smart Farming, a system is built for monitoring the crop field with the help of humidity, temperature, soil moisture sensors and automated the irrigation system. Internet of Things (IoT) is a collection of wireless sensors network finding their applications in the optimization of irrigation and administration of useful nutrients. Wireless Sensor Networks (WSN) are major components of IoT. This irrigation method will avoid the wastage of water, save time and produce more yield. This Proposed method detects the fertilizers and pesticides spraying date and send the alert messages to the user using GSM (Global System for Mobile Communication) for better yield both quantitatively and qualitatively. Drip irrigation method is also adopted to use water sparingly and hence to avoid other problems like eutrophication and green house effect which are commonly caused by flooding of cultivation lands.
\end{abstract}

Keywords: IoT, Smart Farming GSM, WSN, Drip irrigation .

\section{INTRODUCTION}

India has approximately 43.7 million hectare land used for cultivation. Maximum of this land is flood irrigated in the traditional method of agriculture. This farming method is a major reason for the country earning the dubious distinction of being the second largest producer of methane in the world. Smart farming is the urgent need of the nation to produce food of high quality and quantitatively sufficient to meet the requirement of the increasing population and decreasing cultivation area. Hence it is a capital-intensive and hi-tech system. The increasing interest shown by the academicians and industrialists in the field of wireless sensor network and IoT proves the availability of the latent potential in them to revolutionize agri-food sector. More over the optimization

Revised Manuscript Received on February 05, 2020.

* Correspondence Author Palayamkottai, Tirunelveli,, Tamil Nadu, India.

Email: louisaselvakumar@gmail.com

Dr. M. Ramakrishnan, Department of Computer Applications, Madurai Kamarajar University, Madurai, Tamil Nadu, India.

Email: ramkrishod@mkuniversity.org,

A. Abraham N R Singh, Electronics Department, St. John's College, Palayamkottai, Tirunelveli,, Tamil Nadu, India.

Email: abrahamsingh <abrahamsingh@gmail.com

(C) The Authors. Published by Blue Eyes Intelligence Engineering and Sciences Publication (BEIESP). This is an open access article under the CC BY-NC-ND license (http://creativecommons.org/licenses/by-nc-nd/4.0/)
D. Louisa Mary*, Computer Science Department, St. John's College,

and application of the combination of wireless sensor network will result in the improved quality of the soil, increase in the productivity, stimulation in the plant growth, optimization of the fertilizer quantities, monitoring the quantity and quality, maintaining the storage and achieving good distribution.

\section{A. Motivation}

Smart farming is the urgent need of our nation to produce food of high quality and quantitatively sufficient to meet the requirement of the increasing population and decreasing of the cultivation area. Hence it is a capital-intensive and hi-tech system. In IoT based smart farming sensor applications were utilized to achieve accurate monitoring of the vital parameters like humidity, temperature and soil moisture and knowing the values of the fore said parameters with the help of wireless sensors network and comparing them with the standard requirements for a particular crop, optimization of irrigation could be successively achieved. The objectives of the proposed work are a) Development of very accurate sensors to detect the essential parameters in the cultivation land like soil moisture, soil temperature, air humidity. b)Development of software which would collect the pieces of information from the sensors and would apply that to the particular crop that is planted and would suggest the proper supply of materials. c)Development of wireless network to communicate the information obtained from the fore said two objectives to the former's cell phone. d) Development of automated drip irrigation technology and fertilizer and pesticides management technology.

\section{B. Article Structure}

The remaining section of the paper is organized as follows: Section 2 presents the related work and contributions. Proposed architecture is present in Section 3.Section 4 describes the experimental setup and results of performance evaluation. Section 5 summarizes the paper and highlights the open challenges and future directions

\section{RELATED WORK}

Morais et al. [1] implemented a wireless data acquisition network using several Solar-Powered wireless data Acquisition Stations (SPWAS) to collect outdoor and indoor climate data for greenhouses in Portugal. Mizunuma et al. [2] implemented a Wireless LAN in farm field and greenhouse of Japan to monitor plant growth and applied remote control for the production system.

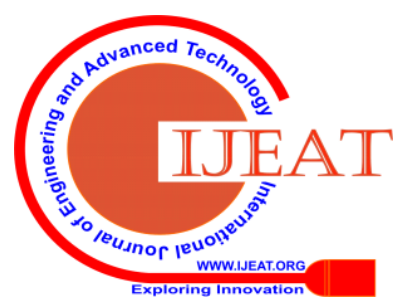


Gang [3] developed a hardware and software of green house data acquisition system based on Bluetooth technology. Wang et al. [4] developed wireless sensor node to acquire temperature, relative humidity and light parameters of a greenhouse.

Kolokotsa et al. [5] developed an intelligent environment and energy management system for greenhouses. In (Sudha et al., 2011)[6], a TDMA-based medium access control (MAC) protocol is used to collect environmental data such as soil moisture and temperature of an irrigation system. Xiaohong et al., 2009[7] describes, a water-saving irrigation system based on fuzzy control technology and WSN. In (Zhang et al., 2011)[8], a calibration method for detecting soil water content based on information sharing is described. Dubey et al.., 2011[9] describes a WSN based remote irrigation control system and automation using dual tone multi frequency (DTMF) code. The system uses signaling to control the water flow for sectored, sprinkler or drip section irrigation. K. A. Patil[10]., maharastra, India, developed an android application which will collect real time data of agriculture production environment and send alerts through Short Massaging Service (SMS) and also give advices for weather pattern. NILESH R.PATEL [11]. ,2014 ,Yavatmal ,India[11] Developed Microcontroller based monitoring system which monitors different environmental parameters like soil moisture, relative humidity and atmospheric temperature. R.Raut ,2018 [12] Pune ,India developed the system which will measure the values of Nitrogen, Phosphorous, and potash from the soil and also monitor the level of soil nutrients and provide the needed quantities of fertilizers. The users will get the updations through e-mail. [13] monitor and drip irrigated to the home agriculture.[14] develop the system which will save the details in clouds and it is controlled by farmer

\section{A. Previous Work and Our Contributions}

This research work is an extended and an updated version of our previous work [13], (published in The Journal of Emerging Technology and Innovative Research). In our previous work, we proposed a system for home agriculture using IoT, which gathers data coming from systems or IoT devices and monitor the information and provide Drip Irrigation. However, these works are not able to apply fertilizers and pesticides on proper date. There is a need for alerting the former to spray fertilizers and pesticides without keenly monitoring the crop daily. The main social application of this work are:

- Development of sensors to detect the essential parameters in the cultivation land like soil moisture, soil temperature, air humidity.

- Development of the software which would collect the pieces of information from the sensors and would apply that to the particular crop that is planted and would suggest the proper supply of materials

- Development wireless network (GSM) to communicate the information obtained from the fore said two objectives to the former's cell phone.

- Development of automated drip irrigation technology and nutrition management technology.

\section{PROPOSED PROBLEM STATEMENT}

This project presents proposed model for smart agriculture to develop real time monitoring system for soil parameters like temperature, atmospheric humidity, soil moisture and to supply the water through drip irrigation method and fertilizers, Pesticides are provided at the time of need in a well defined quantities. It will also be possible to control and monitor various operations of the field remotely from anywhere, anytime by mobile as well as web application.

\section{A. Proposed system Methodology}

\section{Algorithm for Drip Irrigation, Fertilizers and Pesticides spraying}

1. Start.

2. Monitor the soil properties (temperature, soil moisture) in the land.

3. Get the date of sowing the seed.

4. Set the Fertilizers date and pesticides applying date for the seed from the sowing date

5. Transfer of the data from crop fields to the server.

6. At the same time if the temperature and soil moisture values are less than the threshold level solenoid valve automatically opens and drip irrigation is applied to the crop

7. The above process will be continued till it reaches the threshold level.

8. Check the following step to give Fertilizers, Pesticides to the crop

8.1 If (current_date = fertilizer_date)

a) Send the alert sms to the farmer

b) Farmer gets N, P, K liquid fertilizer in correct proportion for the crop and spray it thereafter.

8.2 If (current_date = pesticides_date) then

a) Send the alert sms to the farmer

b) Apply the proper quantities of pesticides to the crop

9.Through mobile application the user can monitor all the above process

10. End.

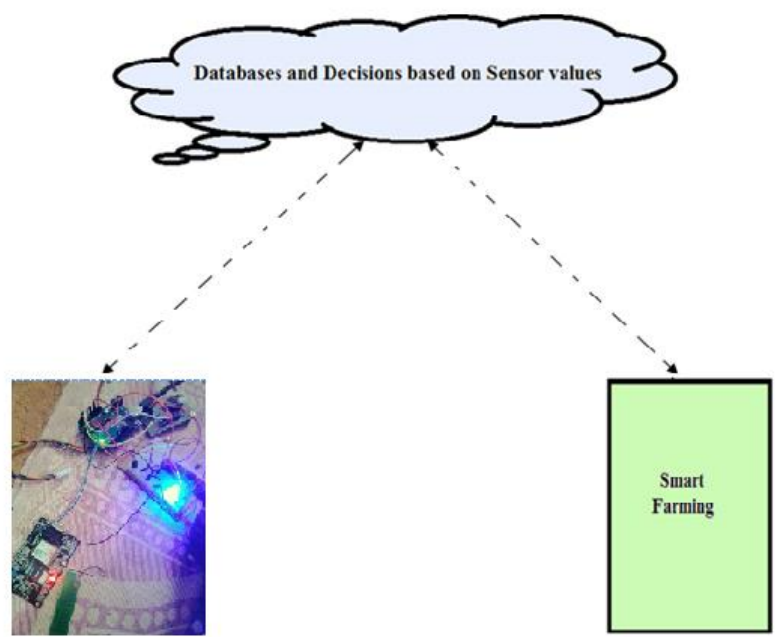

Fig 1:Smart Farming System

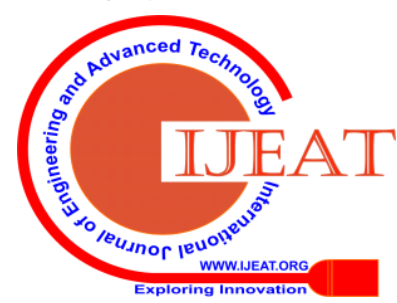


With the help of the above system, the farmer need not manually inspect the soil properties of the crop which is tedious, time consuming and straining.

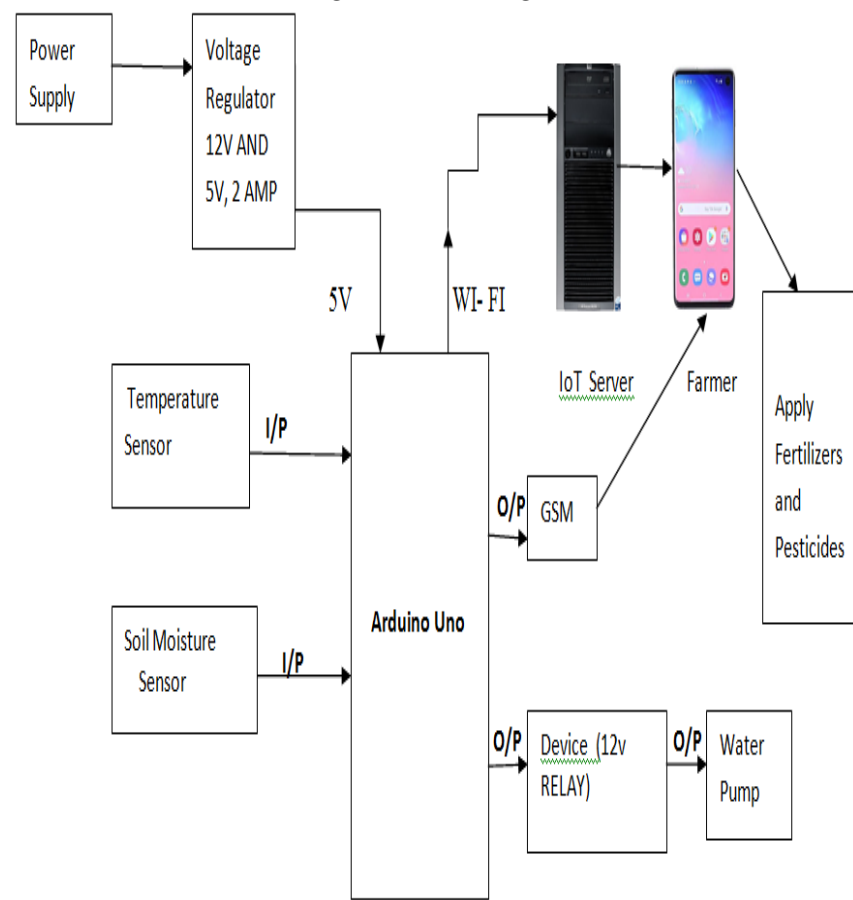

Fig2: Overall Smart Farming Architecture

The above diagram describes the work done in smart farming using the above mentioned algorithm. Use case diagram describes the interaction of users with smart farming . The notation $\quad<<$ include $>>$ used to denote when a use case is described as functionality of another use case. when the use case conditionally adds steps to another first class use case $<<$ Extend $>>$ notation will be used. Extend is used for a use case conditionally adds steps for another first class use case. For example, fertilization is an use case of a smart farming .Checking the fertilizing date process would extend the "Applying Fertilizers" use cases.

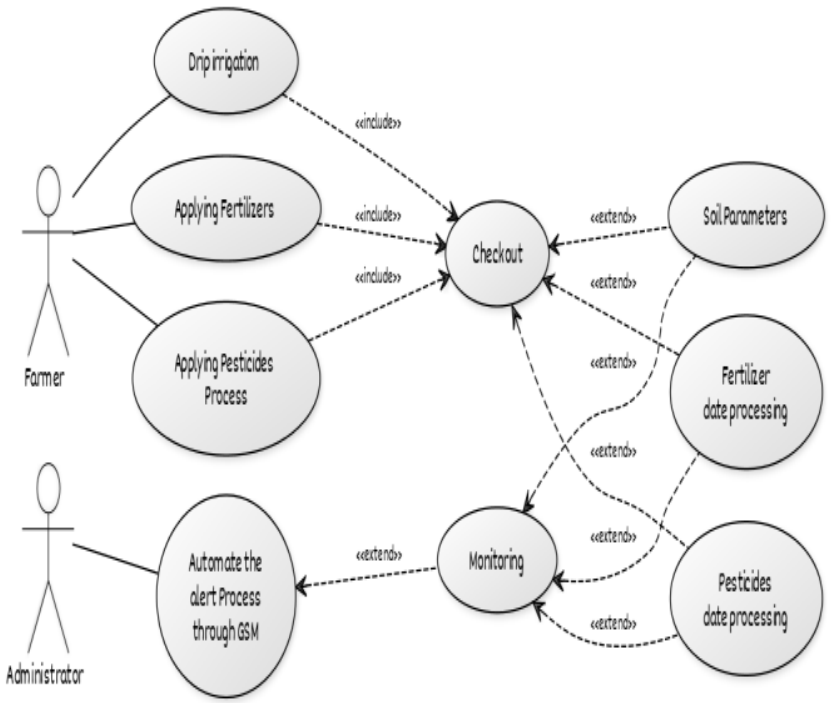

Fig 3:Use case diagram of Smart Farming
Fig 4: Circuit diagram

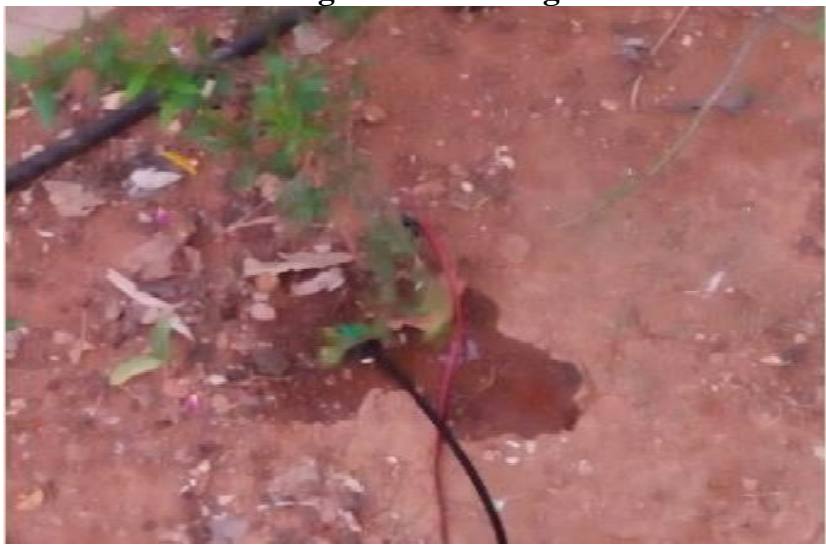

Fig -5 : Drip Irrigation [13]

Fig. 4 and Fig. 5 shows the circuit diagram and the real time implementation of drip irrigation to the plant.

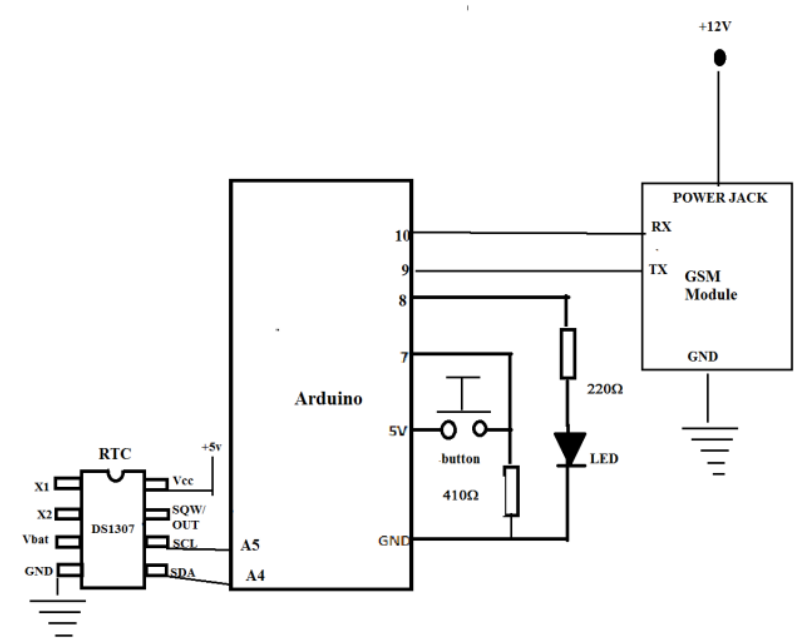

Fig. 6: Circuit diagram for spraying fertilizers and pesticides

In the above diagram Arduino microcontroller is connected to the GSM module and Real Time clock device(RTC). When the button is pressed ,sowing date is stored in Arduino ROM and display the LED light for correct procedure. Real time implementation picture is shown in figure 7.

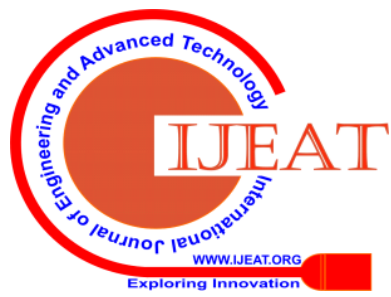




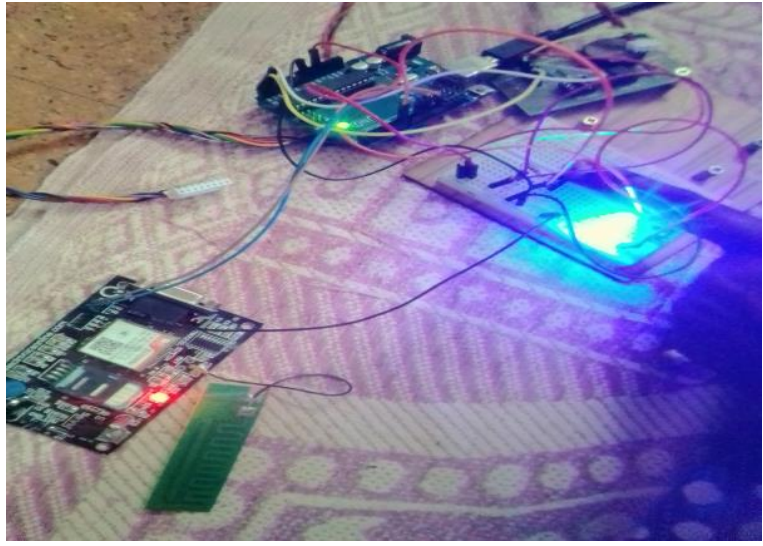

Fig. 7: LED Display for noting the seed date

Here Negative logic is applied to the button but either positive or negative logic can be used.

The circuit diagram for button negative logic is given below:

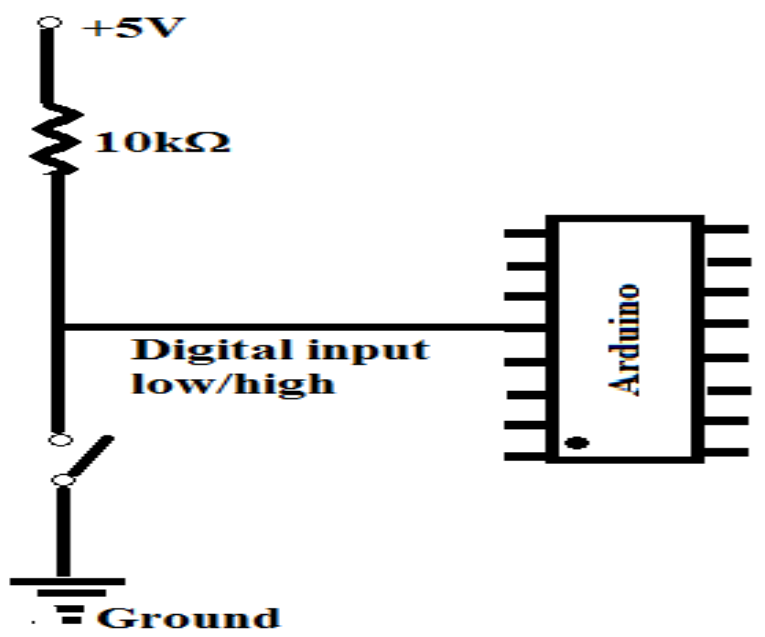

Fig. 8: Negative Logic button circuit

With a pull-up resistor, the digital input will be high if the switch is open and low if the switch is closed (middle of Figure 8). The low current value is taken as logic signal and hence it is called negative logic. Similarly for displaying LED also negative logic is applied. The circuit connection is given below:

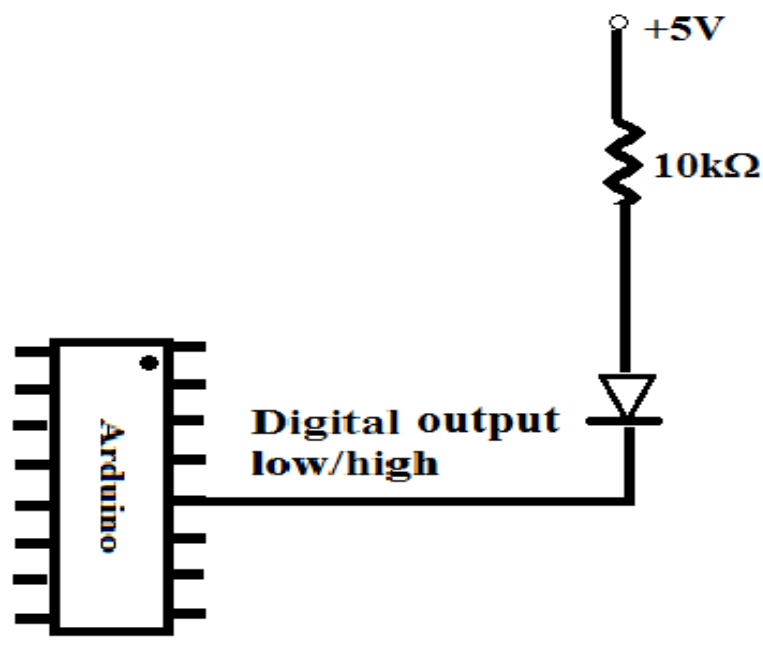

Fig.9 :LED Negative logic diagram

Here the Negative logic means the LED is activated when the software outputs a zero.

When the fertilizer date is reached for the crop, GSM (Global System for Mobile Communications) send the alert message to the former.

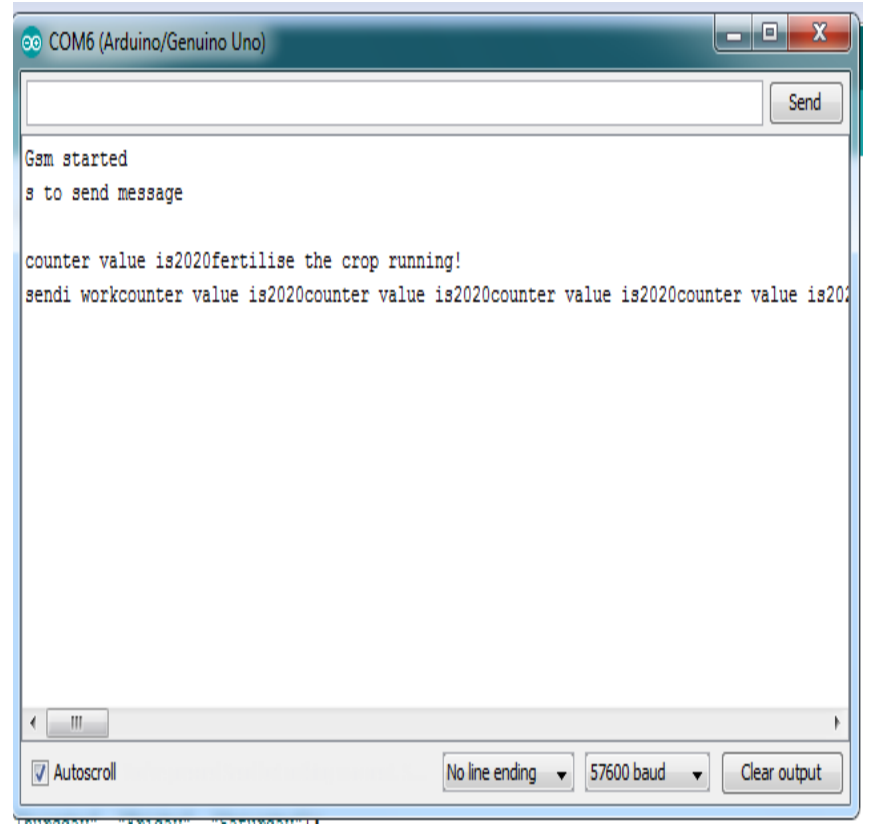

Figure 10:Serial monitor output

The farmer can mix the $\mathrm{N}, \mathrm{P}, \mathrm{K}$ fertilizers in correct ratio for the corresponding crop and spray it. The same way Pesticides can be given to the crop.

\section{CONCLUSION}

The urgent need of the nation to produce food of high quality and quantity to meet the requirement of the increasing population can be met out by integrating agriculture with ICT. By using the proposed approach, Smart Farming can be done by employing drip irrigation whenever it is needed and the updated information can be monitored in the mobile even at their work places. This will make effective usage of water and other fertilizers, consequently will cause increased crop production.

This approach saves time and water and more yield. Fertilizers and pesticides details can increase landscape health, promote deeper root growth, and make the plants more disease resistant. In future, instead of alerting farmers to spray fertilizers and pesticides, the model automatically analysis the soil and take the correct proportion of $\mathrm{N}, \mathrm{P}, \mathrm{K}$ fertilizers to the crop and spray it.

\section{ACKNOWLEDGEMENT}

St. John's college, Palayamkottai,, Tamil Nadu, India

\section{REFERENCES}

1. R. Morais, B. Cunha, M. Cordeiro, C. Serodio, P. Salgado, C. Couto, Solar data acquisition wireless network for agricultural applications, The 19th IEEE Convention of Electrical and Electronics Engineers in Israel, Jerusalem, Israel,1996, pp. 527-530.

2. M. Mizunuma, T. Katoh, S. Hata, Applying IT to farm fields - a wireless LAN, NTT Technical Review 1 (2) (2003) 56-60.

3. L.L.L. Gang, Design of greenhouse environment monitoring and controlling system based on blue tooth technology, Transactions of the Chinese Society for Agricultural Machinery 10 (2006) 97-100.

4. C. Wang, C. Zhao, X. Qiao, X. Zhang, Y. Zhang, The design of wireless sensor networks node for measuring the greenhouse's environment parameters, in: Computer and Computing Technologies in Agriculture, vol. II, Springer, Boston,2008, pp. 1037-1046. 
5. D. Kolokotsa, G. Saridakis, K. Dalamagkidis, S. Dolianitis, I. Kaliakatsos, Development of an intelligent indoor environment and energy management system for greenhouses, Energy Conversion and Management 51 (1) (2010) 155-168

6. Sudha, M., Valarmathi, M., Babu, A., 2011. Energy efficient data transmission in automatic irrigation system using wireless sensor networks. Comput. Electron.Agric. 7 (9), 215-221.

7. Zhang, R., Guo, J., Zhang, L., Zhang, Y., Wang, L., Wang, Q., 2011. A calibration method of detecting soil water content based on the information-sharing in wireless sensor network. Comput. Electron. Agric. 1 (10), 161-168.

8. Xiaohong, P., Zhi, M., Laisheng, X., Guodong, L., 2009. A water-saving irrigation system based on fuzzy control technology and wireless sensor network. Proc. Int. Conf. Wireless Communications, Networking and Mobile Computing, Beijing. pp. 1-4

9. Dubey, V., Dubey, N., Chouhan, S., 2011. Wireless sensor network based remote irrigation control system and automation using DTMF code. Proc. Int. Conf. Communication Systems and Network Technologies. USA. pp. 34-37.

10. K. A. Patil, N. R. Kale 2016,IEEE, Model for Smart Agriculture Using IoT International Conference on Global Trends in Signal Processing, Information Computing and Communication

11. NILESH R.PATEL, Asif Bherani, Gauravkumar N. Raut, Nikesh R. Patel, Pawan D. Kale, Pratik G. Choudhari 2014] IEEE ,Smart Design of Microcontroller Based Monitoring System for Agriculture, International Conference on Circuit, Power and Computing Technologies [ICCPCT]

12. R. Raut, H. Varma ,C. Mulla ,V.R. Pawar, Springer Nature Singapore Pte. Ltd. 2018 Y.-C. Hu et al. (eds.), Intelligent Communication and Computational Technologies, Lecture Notes in Networks and Systems 19, https://doi.org/10.1007/978-981-10-5523-2_7

13. D.Louisa Mary, Dr.M.Ramakrishnan 2019, IOT BASED MONITORING SYSTEM IN HOME AGRICULTURE Journal of Emerging Technologies and Innovative Research 2019 JETIR June 2019, Volume 6, Issue 6 DOI : http://doi.one/10.1729/Journal.22262.

\section{AUTHORS PROFILE}

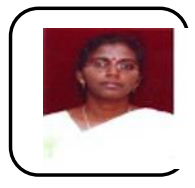

D.Louisa Mary Assistant Professor of Computer Science, St John's College, Palayamkottai has been teaching computer science for the past 13 years. To her credit she has M.Tech degree along with M.CA., M.Phil. She has also qualified SET. Her area of interest is Applications of computers in agriculture.

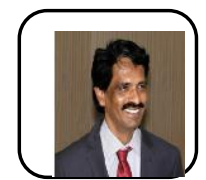

Dr. M. Ramakrishnan is the Head of the Department of Computer Applications Madurai Kamaraj University, Madurai. He has so far produced fifteen PhD's and he has published many papers in reputed journals. He published two books in Computer Science. His area of research is Network Security.

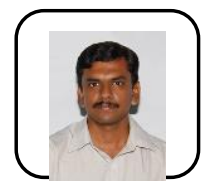

Abraham N R Singh is the Head of the Department of Electronics, St. John's College, Palayamkottai. Received UG degree in Manonmaniam Sundaranar University, India in 2003. Further he received PG degree in Annamalai University, India in 2007. His area of interest is Embedded System. 